Proc. Indian Acad. Sci. (Chem. Sci.), Vol 107, No. 2, April 1995, pp. 157-170.

(C) Printed in India.

\title{
Electronic spectra of some new synthesised methine cyanine dyes
}

\author{
RAGAB M ABU EL-HAMD \\ Chemistry Department, Aswan-Faculty of Science, Aswan, Egypt \\ MS received 27 June 1994; revised 16 February 1995
}

\begin{abstract}
Alstract. New methine cyanine dyes such as monomethine ( $3 \mathrm{a}-\mathrm{c})$, azamethine $(4 a-c)$ and trimethine $(6 a-1)$ and $(8 a-c)$ incorporating a fused pyrazolo $[3,4-d]$ oxazole nucleus were prepared. The new synthesised cyanines were identified by elemental and speciral analyses. The visible absorption spectra of some selected dyes were investigated in pure and mixed solvents as well as in aqueous buffer solutions. Molecular complex formation with ethanol was verified by mixed solvent studies. The variation of absorbance with $\mathrm{pH}$ was utilized for the determination of the $p K a$ values for selected compounds.
\end{abstract}

Keyworda Cyanine dyes; synthesis; solvatochromism; acid-base properties.

\section{Introduction}

Methine cyanine dyes have found various applications as photosensitisers in bluegreen light (Kozlov et al 1972) as laser dyes (Dgdyusha et al 1978) and as analytical reagents over a wide $\mathrm{pH}$ range (Koraiem et al 1986). They are also considered as being suitable for super- and light photographic sensitisers for silver halide emulsion (Konishiroko 1976, 1978).

In the present work, new mono-, aza- and tri-methine cyanine dyes incorporating fused pyrazolo $[3,4-d]$ oxazole nucleus $\underline{3 a-e}, \underline{4 a-c}, \underline{6 a-i}$ and $\underline{8 a-c}$ were prepared to study their spectral behaviours. solvatochromic and acid-base properties anticipating the potential application of such dyes as photosensitizers.

\section{Results and discussion}

Our approach to the synthesis of mono-, aza-and tri-methine cyanines started with the preparation of 5-aryl-3-methyl-1-phenyl pyrazolo [3,4-d] oxazole-2,4-bis ethiodide $\underline{2 a-e}$ via quaternization of 5-aryl-3-methyl-1-phenyl pyrazolo $[3,4-d]$ oxazole derivatives $\underline{1 \mathrm{a}-\mathrm{e}}$ (Koraiem et al 1990) using excess amount of ethyl iodide under controlled conditions. Interaction of $\underline{2 a-e}$ (table 1$)$ and 1 -methyl quinolinium iodide in equimolar ratios under piperidine catalysis gave the corresponding asymmetrical pyrazolo $[3,4-d]$ oxazole-(4)-monomethine cyanine dyes $\underline{3 a-e}$ (scheme 1),

The structures of synthesised compounds were confimed by elemental analysis, IR and 'H NMR (Schimann 1970) spectral data (tables 2-4). The asymmetrical monomethine dyes $\underline{\mathbf{3}}-\mathrm{e}$ were coloured compounds and were partially soluble in non-polar solvents, in which they gave orange solutions with a green fluorescence. They were readily soluble in most polar solvents, giving reddish-brown solutions with intense green fluorescence. They were soluble in conc. $\mathrm{H}_{2} \mathrm{SO}_{4}$ liberating iodine vapour on 


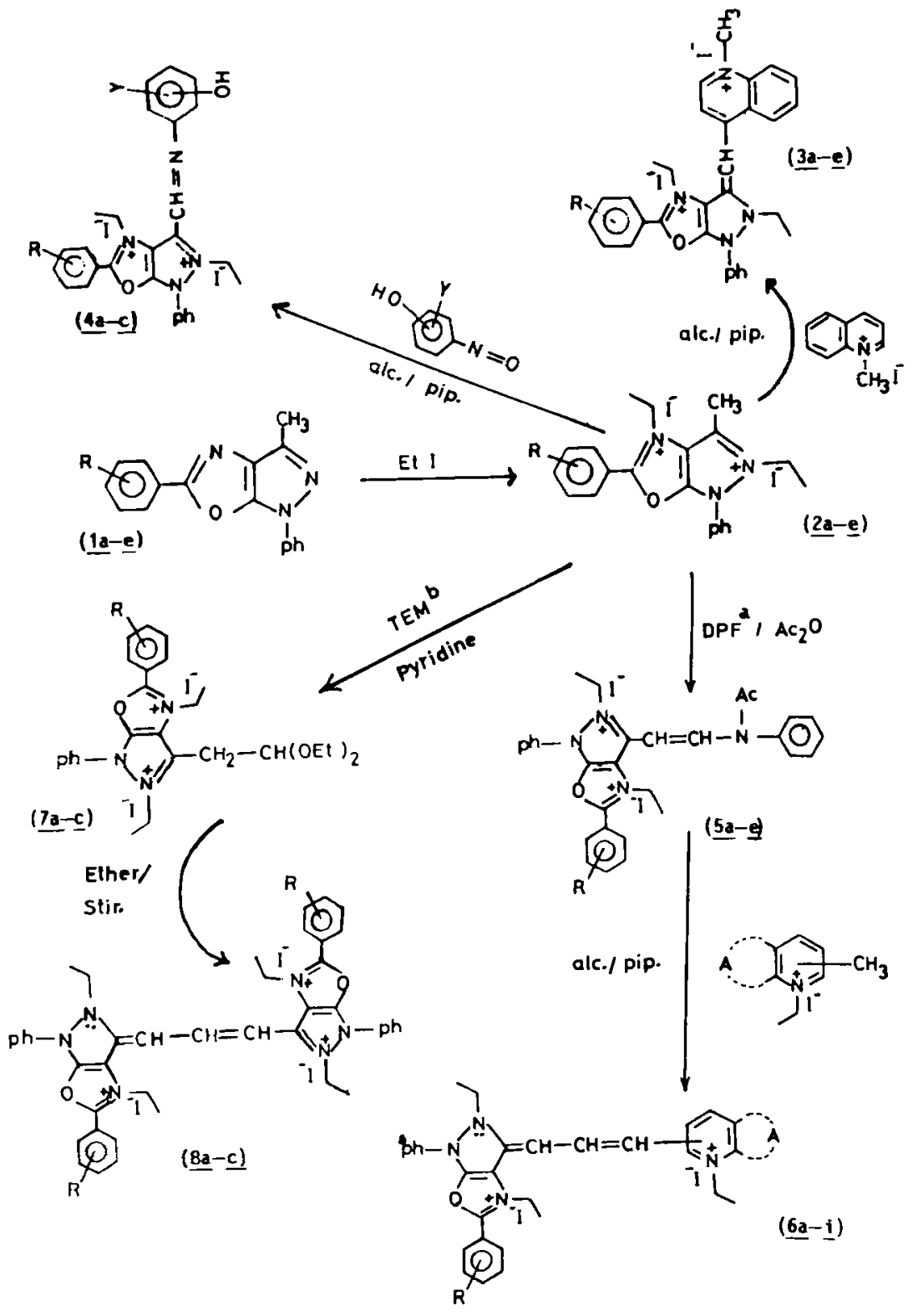

$\underline{1}, \underline{2}, \underline{3}, \underline{5},: \underline{a}, \mathbf{R}=\mathrm{H} ; \underline{\mathrm{b}}, \mathrm{R}=p-\mathrm{OCH}_{3} ; \underline{\mathrm{c}}, \mathrm{R}=p-\mathrm{NO}_{2} ; \underline{\mathrm{d}}, \mathrm{R}=p-\mathrm{OH} ; \underline{\mathrm{e}}, \mathrm{R}=p-\mathrm{Cl}$

$\underline{4 a-c}: \underline{a}, R=p-N_{2}, 4 O H, Y=H$;

b, $R=p-\mathrm{NO}_{2}, 2 \mathrm{OH}, \mathrm{Y}=5,6$-benzo;

6a-i : a $, R=H, A=C_{4} H_{4}-2-y l$ salt;

$\underline{b}, R=H, A=C_{4} H_{4}-4-y l$ salt;

c, $R=p-\mathrm{OCH}_{3}, \mathrm{~A}=\mathrm{C}_{4} \mathrm{H}_{4}-2-y \mid$ salt;

d, $R=p-O_{3} H_{3}, A=C_{4} H_{4}-4$-yl salt;

e, $\mathrm{R}=p-\mathrm{NO}_{2}, \mathrm{~A}=\mathrm{C}_{4} \mathrm{H}_{4}-2$-yl salt; c, $\mathrm{R}=p-\mathrm{NO}_{2}, 2 \mathrm{OH}, \mathrm{Y}=3,4$-benzo.

$\underline{f}, \mathrm{R}=p-\mathrm{OH}, \mathrm{A}=\mathrm{C}_{4} \mathrm{H}_{4}-2-\mathrm{yl}$ salt;

g, $R=p-O H, A=C_{4} H_{4}-4-y l$ salt;

h, $\mathrm{R}=p-\mathrm{Cl}, \mathrm{A}=\mathrm{C}_{4} \mathrm{H}_{4}-2$-yl salt;

I, $\mathrm{R}=p-\mathrm{Cl}, \mathrm{A}=\mathrm{C}_{4} \mathrm{H}_{4}-4$-yl salt.

$\underline{7,8},: \underline{\mathrm{a}}, \mathrm{R}=\mathrm{H} ; \underline{\mathrm{b}}, \mathrm{R}=p-\mathrm{NO}_{2} ; \underline{\mathrm{c}}, \mathrm{R}=p-\mathrm{OH}$.

DPF" : diphenylformamidine.

TEM ${ }^{\mathrm{b}}$ : Triethoxymethane.

\section{Scheme 1}




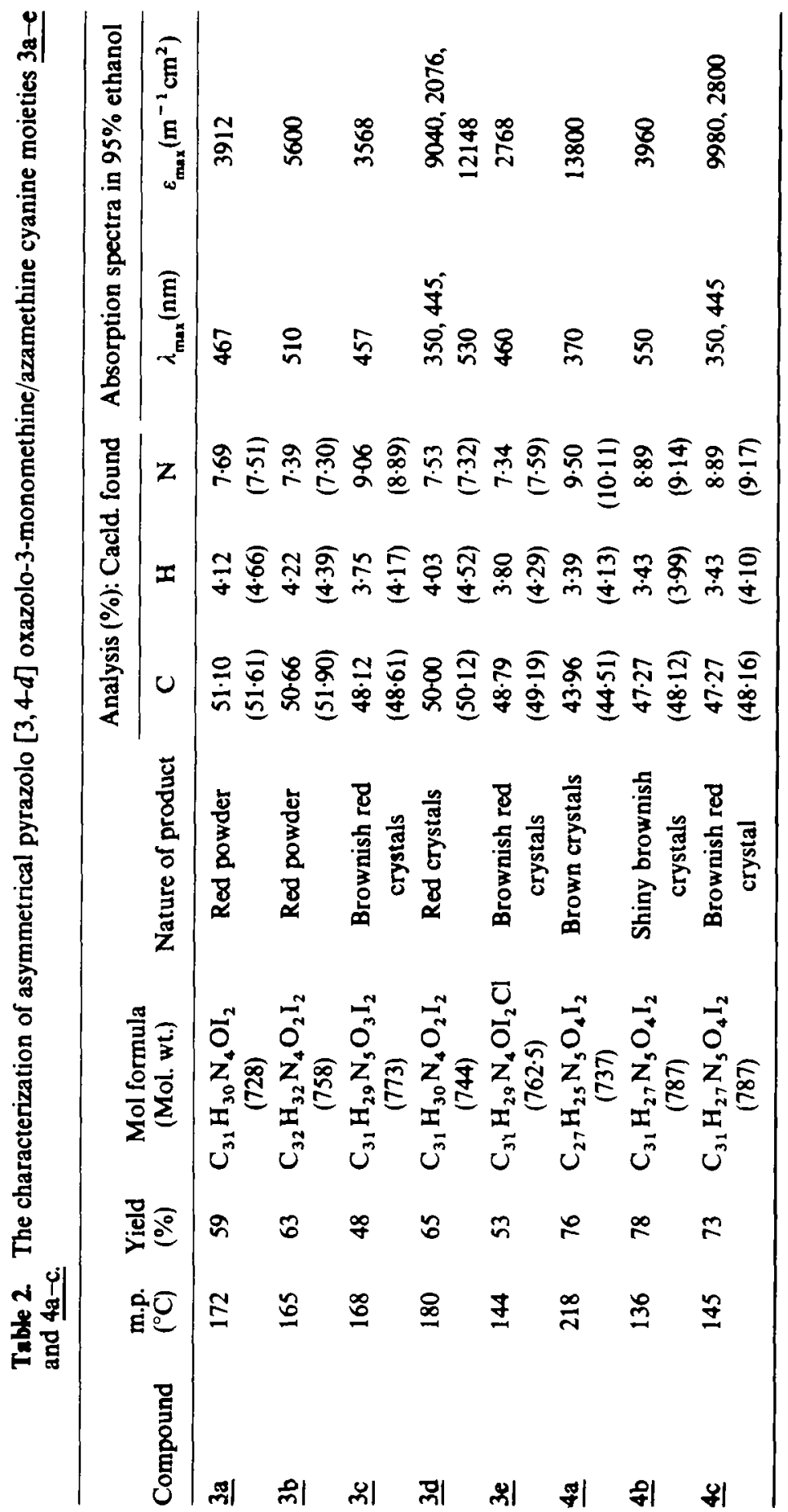




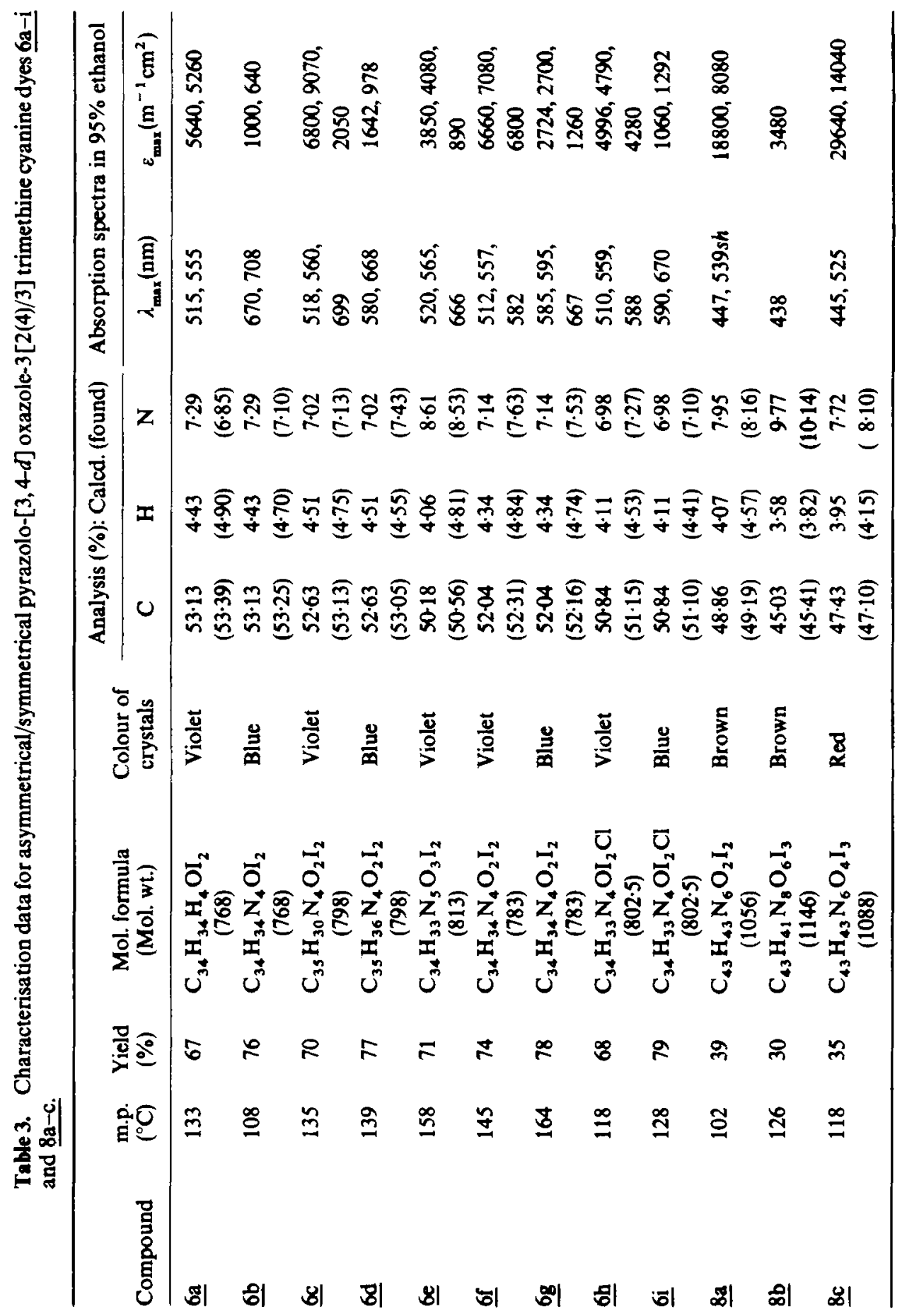


Table 4. IR and ${ }^{1} H$ NMR spectral data of some selected starting compounds like monomethine, azamethine and asymmetrical/symmetrical trimethine cyanine dyes.

\begin{tabular}{|c|c|c|}
\hline $\begin{array}{l}\text { Com- } \\
\text { pound }\end{array}$ & IR spectrum, $v_{\max }^{\mathrm{kBr}}\left(\mathrm{cm}^{-1}\right)$ & ${ }^{1} \mathrm{H}$ NMR $\left(\mathrm{CDCl}_{3}\right)$ spectrum, $\delta(\mathrm{ppm})^{\mathbf{2}}$ \\
\hline$\underline{2 a}$ & $\begin{array}{l}2980-2940 \text { ( } v \text { ethiodide) } \\
1620-1600(v \mathrm{C}=\mathrm{C}) \\
1590-1580(v \mathrm{C}=\mathrm{N}) \\
1180-1210(v \text { oxaxole } \mathrm{C}-\mathrm{O}-\mathrm{C})\end{array}$ & $\begin{array}{l}6 \cdot 5-6 \cdot 9[\mathrm{~m}, 10 \mathrm{H}, \mathrm{Ar}] \\
3 \cdot 3-3 \cdot 8[\mathrm{~m}, 1 \mathrm{OH}, \text { ethiodide }] \\
2 \cdot 4 \quad\left[\mathrm{~s}, 3 \mathrm{H}, \mathrm{CH}_{3}-\right]\end{array}$ \\
\hline$\underline{3 a}$ & $\begin{array}{l}3000-2940(v \text { ethyl and methyl iodide }) \\
1620-1600(v \mathrm{C}=\mathrm{C}) \\
1580(v \mathrm{C}=\mathrm{C}) \\
1180-1210(v \text { oxazole } \mathrm{C}-\mathrm{O}-\mathrm{C})\end{array}$ & $\begin{array}{l}6 \cdot 8-7 \cdot 8[\mathrm{~m}, 17 \mathrm{H}, \mathrm{Ar},(\text { het. })-\mathrm{H} \text { and }=\mathrm{CH}] \\
2 \cdot 1-2 \cdot 6[\mathrm{~m}, 8 \mathrm{H}, \mathrm{ethyl} \text { and methyl iodide }] \\
1 \cdot 3-1 \cdot 5\left[q, 2 \mathrm{H}, \mathrm{CH}_{2}^{*} \mathrm{CH}_{3}\right] \\
1 \cdot 1-1 \cdot 2\left(t, 3 \mathrm{H}, \mathrm{CH}_{2} \mathrm{CH}_{3}^{*}\right]\end{array}$ \\
\hline$\underline{4 a}$ & $\begin{array}{l}3260-3230(v \mathrm{OH}) \\
2980-2940(v \text { ethiodide }) \\
1725-1700(v-\mathrm{CH}=\mathrm{N}) \\
1530-1350\left(v \text { conjugated } \mathrm{NO}_{2}\right) \\
1180-1210(v \text { oxazole } \mathrm{C}-\mathrm{O}-\mathrm{C})\end{array}$ & $\begin{array}{l}7.8-8.4[m, 15 \mathrm{H}, \mathrm{Ar}, \mathrm{CH}=\mathrm{N}, \& \mathrm{OH}] \\
1.9-2.9[\mathrm{~m}, 10 \mathrm{H}, \text { ethiodide }]\end{array}$ \\
\hline$\underline{6 a}$ & $\begin{array}{l}2980-2940 \text { ( } v \text { ethiodide }) \\
1680-1660(v \text { CH=CH-CH }=) \\
1180-1210(v \text { oxazole C-O-C) } \\
840-820(v \text { mono-sub.Ar. })\end{array}$ & $\begin{array}{l}6.5-6.9[\mathrm{~m}, 16 \mathrm{H}, \mathrm{Ar}(\text { het. })-\mathrm{H}] \\
1.7-2.4[\mathrm{~m}, 10 \mathrm{H}, \text { ethiodide }] \\
1.4-1.6[\mathrm{t}, 3 \mathrm{H},=\mathrm{CH}-\mathrm{CH}=\mathrm{CH}-] \\
0.9-1.3\left[\mathrm{~m}, 5 \mathrm{H}, \mathrm{CH}_{3} \mathrm{CH}_{2}\right]\end{array}$ \\
\hline$\underline{8 a}$ & $\begin{array}{l}2980-2940(v \text { ethiodide }) \\
1680-1660(v \mathrm{CH}=\mathrm{CH}-\mathrm{CH}=) \\
1610-1600(v \mathrm{C}=\mathrm{C}) \\
1180-1210(v \text { oxazole } \mathrm{C}-\mathrm{O}-\mathrm{C}) \\
840-820(v \text { mono-sub.Ar. })\end{array}$ & $\begin{array}{l}7 \cdot 1-8 \cdot 2[\mathrm{~m}, 20 \mathrm{H}, \mathrm{Ar} .] \\
2 \cdot 3-2 \cdot 5[t, 3 \mathrm{H}, \mathrm{CH}=\mathrm{CH}-\mathrm{CH}=] \\
1 \cdot 6-1 \cdot 9[\mathrm{~m}, 15 \mathrm{H}, \mathrm{ethiodide}] \\
1 \cdot 1-1 \cdot 4\left[\mathrm{~m}, 5 \mathrm{H}, \mathrm{CH}_{3} \mathrm{CH}_{2}-\right]\end{array}$ \\
\hline
\end{tabular}

"Abbreviations; $s$, singlet; $d$, doublet, $t$, triplet; $m$, multiplet

replacement of the acetanilido group by 1-ethyl quinolinium salt with interchange of the quaternary centres on the molecules. See scheme 1.

The structures of the synthesised asymmetrical $3[2(4)]$ trimethine cyanines $6 a-i$ were established by elemental analysis, IR and ${ }^{1}$ H NMR (Schimann 1970) spectral data (tables 3,4$)$. They are partially soluble in non-polar solvents exhibiting reddish-violet solutions with slight green fluorescence. They are soluble in polar solvents giving deep violet solutions with intense green fluorescence. They liberate iodine in warm conc. $\mathrm{H}_{2} \mathrm{SO}_{4}$. The colour of their ethanolic solutions is discharged on acidification.

The visible absorption spectra of $6 \mathrm{a}-\mathrm{i}$ in $95 \%$ ethanol exhibit absorption bands intensified and more bathochromic for quinolinium-4-yl salts than 2-yl analogues. Such absorption bands undergo bathochromic or hypsochromic shifts on substitution of aryl oxazole either with electron donating (e.g. $p-\mathrm{OCH}_{3}, p-\mathrm{OH}$ ) or withdrawing (e.g. $p$ - $\mathrm{NO}_{2}$ ) groups respectively (table 3 ). This is due to the same reasons as suggested for compounds $\underline{3 \mathrm{a}-\mathrm{e}}$.

Attention was thus turned to novel Knoevenagel-type reactions (Vogel 1956) at the 3-methyl group of 5-aryl-1-phenyl-3-methyl pyrazolo [3,4-d] oxazole-2,4-bis ethyl iodide $\underline{2 a-e}$. These salts $\underline{2 a}, \underline{2 c}$ and $\underline{2 d}$ when heated under reflux in pyridine with triethoxymethane(TEM) yielded orange crystalline products identified as symmetrical trimethine cyanine dyes $\underline{8 a-c}$. (See scheme 1). 
The structures of symmetrical trimethine cyanines $\underline{8 a-c}$ were established by elemental analysis, IR and ${ }^{1} \mathrm{H}$ NMR (Schimann 1970) spectral data (tables 3, 4). They are orange coloured compounds, fairly soluble in polar and non-polar organic solvents. They are soluble in conc. $\mathrm{H}_{2} \mathrm{SO}_{4}$ liberating iodine vapour on heating.

As was observed in the electronic absorption spectra of either asymmetrical monoand trimethine, the visible absorption spectra of symmetrical trimethine cyanine dyes $\underline{8 a-c}$ in $95 \%$ ethanol exhibit single broad absorption band. Either its position or molar extinction coefficient is influenced by the aryl substituents attached to the pyrazolo$[3,4-d]$ oxazole moieties. (See table 3).

2.1 Solvatochromic behaviour of asymmetrical pyrazolo [3, 4-d] oxazolium-3(4)-monomethine cyanine dye $3 d$ and/or 3(2)-trimethine cyanine of in pure solvents

The $\lambda_{\max }$ and $\varepsilon_{\max }$ values of the absorption bands due to different electronic transitions with the solute molecules $\underline{3 \mathrm{~d}}$ and $\underline{6 f}$ obtained in pure solvents of different dielectric constants (Weast and Astle 1980) (viz. $\mathrm{H}_{2} \mathrm{O}, \mathrm{DMF}, \mathrm{EtOH}, \mathrm{CHCl}_{3}$, acetone, dioxane and benzene), are represented in table 5 .

The spectra of compounds $\underline{3 \mathrm{~d}}$ and $\underline{6 f}$ in ethanol consist of three essential absorption bands located at longer wavelengths in the visible region attributed to $n-\pi^{*}$ transitions and intramolecular charge transfer (CT) transitions (Mahmoud et al 1975).

Careful examination of the results reported in table 5 reveals that the bands corresponding to $\mathrm{CT}$ transitions show a red shift on changing the organic solvent from EtOH to dioxane, benzene, acetone, DMF and $\mathrm{CHCl}_{3}$ (Koraiem et al 1990). The unexpected blue shift observed in the $\lambda_{\max }$ of CT bands in ethanol can be mainly explained as a result of intermolecular $\mathbf{H}$-bond formation between ethanol and the lone pair electrons of the oxazole oxygen atom. Thus, the mobility of the $\pi$-electrons to the conjugated pathway is decreased and consequently the observed high excitation energy

Table 5. Electronic absorption spectral ${ }^{\alpha}$ characteristics of the monomethine cyanine $\underline{3 \mathrm{~d}}$ and the trimethine cyanine $\underline{6} \mathrm{f}$ in single solvents at $25^{\circ} \mathrm{C}$.

\begin{tabular}{lccccccc}
\hline Compound & $\mathrm{H}_{2} \mathrm{O}$ & $\mathrm{DMF}$ & $\mathrm{EtOH}$ & $\mathrm{CHCl}_{3}$ & Acetone & Dioxane & $\mathrm{C}_{6} \mathrm{H}_{6}$ \\
\hline 3d & 340 & 347 & 350 & 335 & 335 & $345 s h$ & 335 \\
& $(7300)$ & $(800)$ & $(9040)$ & $(6810)$ & $(7100)$ & $(7000)$ & $(8000)$ \\
& - & 405 & - & 414 & 410 & 413 & 414 \\
& - & - & 445 & $458)$ & 445 & - & 465 \\
& & & $(2076)$ & $(7100)$ & $(7500)$ & & $(7400)$ \\
& 512 & 550 & 530 & 555 & 548 & 545 & 552 \\
& $(9600)$ & $(14100)$ & $(14148)$ & $(12600)$ & $(13300)$ & $(12100)$ & $(12200)$ \\
& 515 & 515 & 512 & 520 & 519 & $515 s h$ & 520 \\
& $(5600)$ & $(6200)$ & $(6660)$ & $(6010)$ & $(6010)$ & $(4910)$ & $(6000)$ \\
& 555 & 563 & 557 & 562 & 561 & - & - \\
& $(6018)$ & $(6730)$ & 7030 & 7100 & $(6820)$ & & \\
& 580 & 585 & 582 & - & 590 & 588 & 585 \\
& $(6020)$ & $(6800)$ & $(6800)$ & & $(6910)$ & $(6400)$ & $(7200)$ \\
& - & 615 & - & 608 & - & 622 & 630 \\
& & $(6400)$ & & $(6820)$ & & $(6510)$ & $(5800)$ \\
\hline & & & & & &
\end{tabular}

- Data shown are $\lambda_{\max }(\mathrm{nm})$ with $\varepsilon_{\max }\left(\mathrm{mol}^{-1} \mathrm{~cm}^{2}\right)$ in parentheses; sh $=$ shoulder 

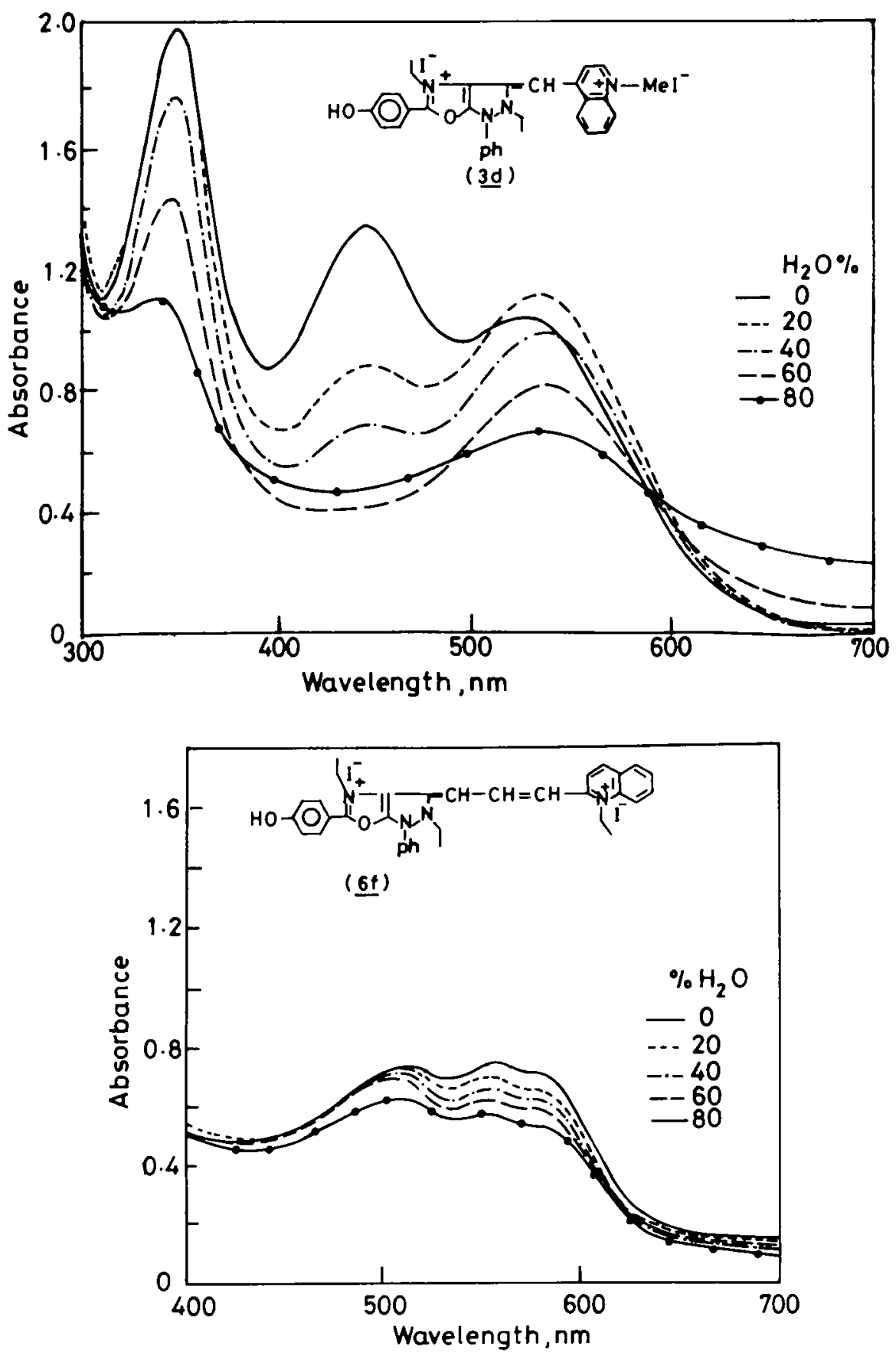

Figure 1. The absorption spectra of two selected cyanines $(3 \mathrm{~d}, \underline{\mathbf{4 f}})$ recorded in ethanol-water mixtures. 
needed in ethanolic medium relative to the other organic solvents used. The blue shift observed in $\lambda_{\max }$ of the CT bands of compounds $3 \mathrm{~d}$ and $6 \mathrm{f}$ in water (dielectric constant $=78.54$ ) (Weast et al 1980) relative to ethanol (24.3), as well as the lower extinction, can be ascribed to the stronger interaction of water molecule with the lone pair of the electrons on the oxygen of oxazolo nucleus through $\mathrm{H}$-bonding (Koraiem et al 1990, 1991).

2.2 Spectral behaviour of pyrazolo -[3,4-d]-oxazolium-3(4)-monomethine and/or 3(2)trimethine cyanine dyes $\underline{3 d}$ and $\underline{6 f}$ in mixed solvents

Spectra in mixed solvents were recorded in order to evaluate the possibility of the formation of a hydrogen-bonded solvated complex between the solute molecules and ethanol or water. The visible spectra of compounds $\underline{3 d}$ and $\underline{6 f}$ in EtOH containing progressively increasing quantities of $\mathrm{H}_{2} \mathrm{O}$, showed (figure 1), a decrease in the absorbance of the CT band with increasing proportion of $\mathrm{H}_{2} \mathrm{O}$ and the disappearance of the absorption band located at $\lambda_{\max } 445 \mathrm{~nm}$ for $\underline{3 \mathrm{~d}}$.

Evidence for hydrogen-bond formation between the solute molecules and ethanol or water can be obtained from data on the free energy change of formation $(\Delta G)$ of the molecular complex, calculated using the relationship (1).

$$
\Delta G=-R T \ln K_{s} .
$$

The stability constant $\left(K_{f}\right)$ of the complex can be determined from a consideration of the behaviour in mixed solvents (Koraiem et al 1990, 1991) using the relationship (2), figure 2.

$$
\log K_{f}=\log \frac{A-A_{\min }}{A_{\max }-A}-n \log C_{\mathrm{EIOH}}
$$

The values of $K_{f}$ and $\Delta G$ of the hydrogen-bonded molecular complex liable to be formed in solution between the molecules of compound $\underline{3 \mathrm{~d}}$ and $\mathrm{EtOH}$ or $\mathrm{H}_{2} \mathrm{O}$ are as follows.

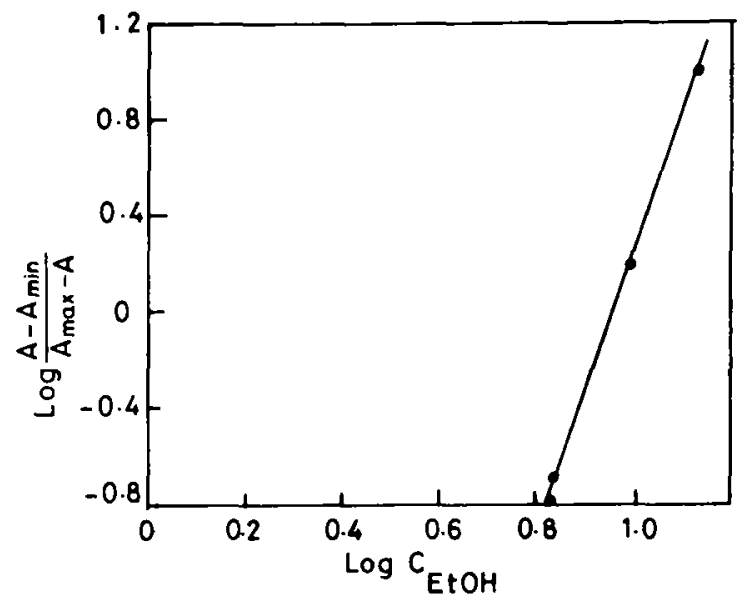

Figure 2. $\log \left(A-A_{\min }\right) /\left(A_{\max }-A\right)$ vs $\log C_{\mathrm{E}_{1 O H}}$ for compound $\underline{3 \mathrm{~d}}$ in $\mathrm{H}_{2} \mathrm{O}-\mathrm{EtOH}$ mixtures at $25^{\circ} \mathrm{C}$. 


\begin{tabular}{|c|c|c|c|c|c|c|c|}
\hline \multirow[b]{2}{*}{ System } & \multicolumn{2}{|c|}{$\begin{array}{l}\text { Excitation } \\
\text { energy } \\
\left(\mathrm{kJ} \mathrm{mol}^{-1}\right)\end{array}$} & \multirow{2}{*}{$\begin{array}{c}\text { Orientation } \\
\text { energy } \\
\left(\mathrm{kJ} \mathrm{mol}^{-1}\right)\end{array}$} & \multirow{2}{*}{$\begin{array}{c}\text { H-bond } \\
\text { energy } \\
\left(\mathrm{kJ} \mathrm{mol}^{-1}\right)\end{array}$} & \multirow[b]{2}{*}{$n$} & \multirow[b]{2}{*}{$\boldsymbol{K}_{\boldsymbol{J}}$} & \multirow[b]{2}{*}{$\begin{array}{c}\Delta G \\
\left(\mathrm{~kJ} \mathrm{\textrm {mol } ^ { - 1 }}\right)\end{array}$} \\
\hline & $\begin{array}{l}\text { Pure } \\
\mathrm{H}_{2} \mathrm{O}\end{array}$ & $\begin{array}{l}\text { Pure } \\
\text { EiOH }\end{array}$ & & & & & \\
\hline $\mathrm{H}_{2} \mathrm{O}$-EtOH & $64 \cdot 27$ & $75 \cdot 26$ & 1.93 & $5 \cdot 23$ & 1 & 10 & 1.25 \\
\hline
\end{tabular}

The values of $K_{f}, \Delta G$ and $n$ (the number of EtOH or $\mathrm{H}_{2} \mathrm{O}$ molecules which are complexed with the solute molecule) indicate that a 1:1 complex is formed.

On plotting the excitation energy $(E)$ of the CT band in the mixed solvent versus the ethanol mole fractions (figure 3), a broken line (Chemla et al 1987) with three segments is obtained. The first segment indicates the orientation of the solvent molecules around the solute molecule. The second segment represents the molecular complex formation, while the third segment represents the steady state of the energy attained after the complete formation of the molecular complex. The values of orientation and H-bond energies are given above.

\subsection{Acid-base properties}

The ethanolic solutions of new synthesised cyanine dyes $\underline{3 d}, \underline{6 f}$ and $\underline{8 b}$ give a permanent colour in basic medium which was discharged on acidification. This prompted us to study their spectral behaviour in different buffer solutions in order to choose suitable pH media when used as photosensitizers.

The electronic absorption spectra of cyanine dyes $\underline{3 d}$, $6 f$ and $\underline{8 b}$ in universal buffer solutions of varying $p \mathrm{H}(2.53-12.08)$ undergo hypsochromic shifts in the absorption band in acidic medium (low $\mathrm{pH}$ ) and bathochromic shift in alkaline medium (high $\mathrm{pH}$ ) (figure 4).

The bathochromic shift in alkaline medium is due to a relatively increased negative charge density on the pyrazolo- $[3,4-d]$ oxazole system. The bands are hypsochromjcally shifted in acidic medium due to protonation of the nitrogen/oxygen heteroatoms

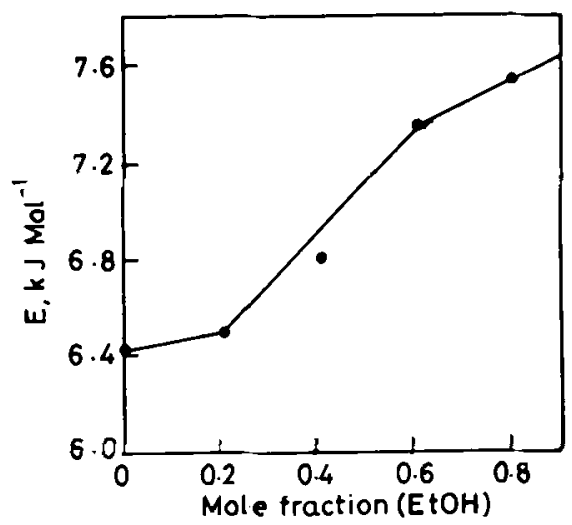

Figure 3. CT band excitation energy $(E)$ vs EtOH mole fraction for compound $\underline{3 d}$ in $\mathrm{H}_{2} \mathrm{O}$-EtOH mixtures at $25^{\circ} \mathrm{C}$. 

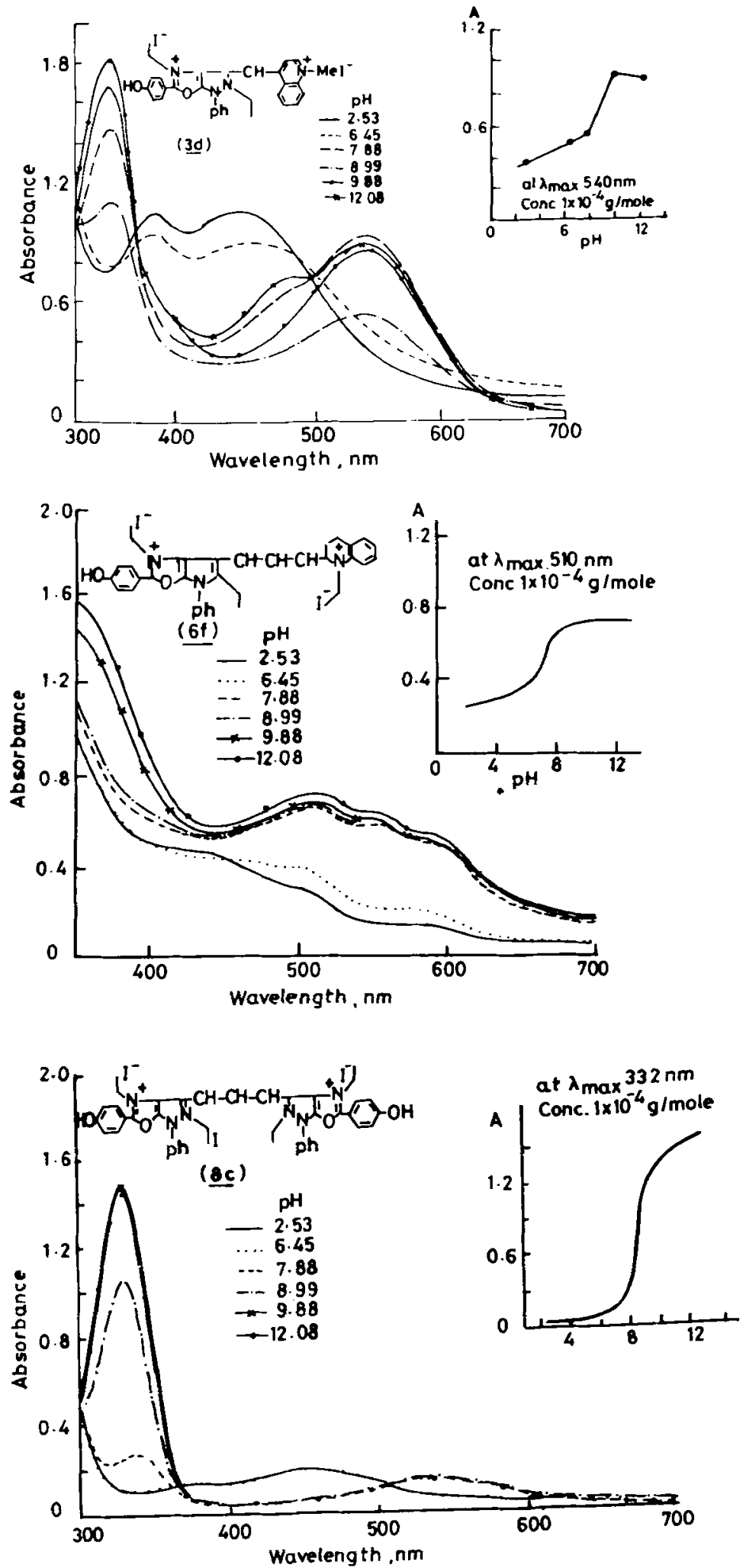

Figure 4. The variation of absorption spectra of selected cyanines (3d, $\underline{4 f}$ and $\underline{8 c})$ with changes in $\mathrm{pH}$ of the medium. 
of the nuclei or of the mono- and trimethine systems at low $p H . C T$ interaction within the protonated form is thus difficult. On the other hand, as the $p \mathrm{H}$ of the medium increases, deprotonation occurs and the CT interaction within the free base is facilitated (figure 4).

The acid dissociation or protonation constants of cyanine compounds under study $\underline{3 \mathrm{~d}}, \underline{6 \mathrm{f}}$ and $\underline{8 \mathrm{~b}}$ have been determined in order to ensure the optimal $\mathrm{pH}$ in the application as photosensitizer. Such determination was measured on plotting the variation of absorbance with $\mathrm{pH}$ using the spectrophotometric half-height limiting absorbance and Colleter methods (Colleter 1960). The effectiveness of the compounds as photosensitizers increases when they are present in the ionic form which have higher planarity (Mahmoud et al 1975). The results of the $p K a$ values of the cyanines $3 \mathrm{~d}(8 \cdot 8)$ is higher than those of $(\underline{6 f},(7 \cdot 1) \& \underline{8 b},(8 \cdot 2)$ respectively. This behaviour refers to the higher planarity and greater stability of monomethine cyanine type $\underline{3 d}$ which favour the intramolecular charge transfer. This leaves a lower negative charge density on the nucleus resulting in weaker bonding of the proton. Such dyes might be suggested to be more sensitive as photosensitizers than their analogues $\underline{6 f}, \underline{8 \mathrm{~d}}$.

\section{Experimental}

\subsection{General}

All melting points are uncorrected. Elemental analysis were carried out at the Microanalytical Centre (Cairo University). IR spectra determined with Perkin Elemer Infrared $127 \beta$ spectrophotometer (Cairo University). Visible, solvatochromic and acid-base behaviours were recorded on Shimadzu-UV-Vis-240 recording spectrophotometer using $1 \mathrm{~cm}$ cells (Faculty of Science, Aswan) while ${ }^{1} \mathrm{HNMR}$ spectra were recorded with EM-390 $90 \mathrm{HHZ}$ NMR spectrometer (Cairo University).

Stock solutions $\left(10^{-3} \mathrm{M}\right)$ of selected cyanines were prepared by dissolving the recrystallised dyes in ethanol. Solutions of lower molarities used in spectral measurements were obtained by appropriate dilution. The aqueous universal buffer solutions of

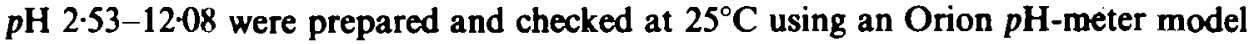
$60 / \mathrm{A}$ accurate to $\pm 0.005 \mathrm{pH}$ units.

5-Aryl-3-methyl-1-phenylpyrazolo $[3,4-d]$ oxazole deriatives $\underline{1 \mathrm{a}-\mathrm{e}}$ were prepared according to Koraiem et al (1990).

3.2 Synthesis of 5-aryl-3-methyl-1-phenyl pyrazolium [3,4-d]-oxazolium-2,4-bis ethyl iodide $\underline{2 a-e}$

Pure samples of compounds $1 \mathrm{a}-\mathrm{e}$ were suspended in excess ethyl iodide and heated in sealed tubes at $140^{\circ} \mathrm{C}$ for $3 \mathrm{~h}$. The tubes were then cooled, opened and the products $2 \mathrm{a}-\mathrm{e}$ collected, washed with ether and crystallized from ethyl alcohol to give orange-tobrown crystals (table 1).

3.3 Synthesis of asymmetrical pyrazolo $[3,4-d]$ oxazolo-3(4)-mono-methine cyanine dyes $\underline{3 a-e}$

Equimolar amounts $(0-01 \mathrm{~mol})$ of $2 \mathrm{a}-\mathrm{e}$ and quinoline methyl iodide were dissolved in ethanol ( $35 \mathrm{ml})$, then piperidine (3-5 drops) was added. The reaction mixture was refluxed for 6-8h. The mixture was filtered hot, evaporated to half its volume and cooled. The products were precipitated after dilution with water, collected and 
crystallized from aqueous ethanol to give the corresponding monocyanine dyes $\underline{3 a-e}$. The results are listed in table 2.

\subsection{Synthesis of asymmetrical pyrazolo [3,4-d] oxazole-3-azamethine cyanines $\underline{4 a-c}$}

Equimolar ratios of $\underline{2 b}$ and $p$-nitroso phenol, $\alpha(\beta)$-nitroso- $\beta(\alpha)$-naphthol compounds $(0-01 \mathrm{~mole})$ were dissolved in ethanol $(40 \mathrm{ml})$ then piperidine $(3-5 \mathrm{drops})$ was added. The reaction mixture was refluxed for $10-12 \mathrm{~h}$, filtered hot, and concentrated to dryness. The precipitated products were washed and crystallized from ethanol. The results are listed in table 2.

3.5 Synthesis of asymmetrical pyrazolo [3,4-d] oxazolium-3-[2(4)]-trimethine cyanine moieties $\underline{6 a-i}$

3.5a Equimolar ratios of $2 \mathrm{a}-\mathrm{e}$ and diphenylformamidine (DPF, 0.01 mole) were dissolved in $\mathrm{Ac}_{2} \mathrm{O}$. The reaction mixture was refluxed for 4-6h, filtered hot, evaporated and cooled. The products were precipitated with water, filtered off, washed with $\mathrm{H}_{2} \mathrm{O}$ and crystallized from aqueous ethanol to give the intermediate compounds $\underline{5-e}$.

$3.5 b$ A mixture of compounds $5 \mathrm{a}-\mathrm{e}$ and 2 (4)-methyl quaternary salts (quinaldine and lipidine ethyl iodide), $(0-01$ mole $)$ were dissolved in ethanol $(40 \mathrm{ml})$, then piperidine $(2-3$ drops) was added. The reaction mixture was refluxed for $6-8 \mathrm{~h}$, filtered hot, concentrated and cooled. The product precipitated with water and crystallized from ethanol to give compounds $\underline{6 \mathrm{a}-\mathrm{i}}$. The results are listed in table 3 .

3.6 Synthesis of symmetrical pyrazolo [3,4-d] oxazolium-3(3)-trimethine cyanine moieties $\underline{8} \underline{a}-c$

3.6a Bimolar ratios of $\underline{2 \mathrm{a}}, \underline{2 \mathrm{c}}$ and $\underline{2 \mathrm{~d}}$ and triethoxymethane (TEM, 0-01 mole) were dissolved in pyridine. The reaction mixture was refluxed for $3-5 \mathrm{~h}$, filtered hot and evaporated to give the non-isolated intermediate compounds $\underline{7 a-c}$.

3.6b Triturated the non-isolated intermediate compounds $\underline{7 a-c}$ with ether and stirred. The stirred mixture was evaporated to give a coloured precipitate, filtered off and crystallized from ethanol to give the corresponding symmetrical trimethine cyanines $\underline{8 \mathrm{a}-\mathrm{c}}$. The results are listed in table 3 .

\section{Conclusions}

Spectral attention has been focused on the spectra, solvatochromic and acid-base properties of some selected cyanine dyes under investigation as a criterion of their photosensitization effects. Such effects are influenced by the nature of biheterocyclic aryl substituents, linkage position, solvent used and acid-base environment. Thus, cyanine dyes having electron donating substituents are more sensitive as photosensitizer than those having electron deactivating one. In view of linkage position, the asymmetrical 3(4)-trimethine cyanines are more sensitive as photosensitizers when compared with 3(2)-analogues. Also, within trimethine cyanines, asymmetrical trimethine cyanines are more sensitive when compared with their symmetrical analogues. On the other hand, with respect to phenolic azamethine cyanines $\underline{4 a-c}$ the 
sensitization effect as criterion from their spectral behaviour is of the following order (2-naphthol > 1-naphthol > phenol) (table 2).

These dyes are solvent dependent and $\mathrm{pH}$ sensitive, they exhibit general solutesolvent interaction depending on the dielectric constants of the solvent used as well as specific solute-solvent interaction. This includes hydrogen-bonding and molecular complex.

Asymmetrical monomethine dye $\underline{3 \mathrm{~d}}$ is more $\mathrm{pH}$-sensitive than asymmetrical (symmetrical)-trimethine cyanine dyes $\underline{6 b}$ and $\underline{8 b}$ respectively and might be used as an analytical reagent in protometric titration.

\section{Acknowledgement}

The author expresses his appreciation to Prof. Dr A I M Koraiem of the Physical Organic Chemistry Department and Prof. Dr Z H Khalil of the Organic Chemistry Department for their guidance on cyanine dyes including structure and physical properties and their endless efforts for the recasting of this paper.

\section{References}

Chemla D S and Zyss J 1987 Nonlinear optical properties of organic molecules and crystals (New York: Academic Press)

Colleter J C 1960 Ann. Chim. (France) 5415

Dgdyusha G G, Zubarovsikii V M, Moreiko O V, Prahonskaya O V, Sych E D, Tikhonov E A and Khodot G P 1978 USSR Patent 568318; 1979 Chem. Abstr. 90 46509j

Konishiroko 1976 Konishiroko Photo Industry Ltd. Ger. Offen 2600968; 1977 Chem. Abstr. 86 49175a

Konishiroko 1978 Konishiroko Photo Industry Ltd. Ger. Offen 2734335; 1978 Chem. Abstr. 88 $161442 \mathrm{c}$

Koraiem A I M, Khalil Z H and Abu El-Hamd R M 1986 J. Chem. Technol. Biotechnol. 36473

Koraiem A I M, El-Maghraby M A and Abu El-Hamd R M 1990a Dyes Pigm. 1459

Koraiem A I M, Girgis M M, Khalil Z H and Abu El-Hamd R M 1990b Croat. Chem. Acta 63603

Koraiem A I M, Girgis M M, Khalil Z H and Abu El-Hamd R M 1990c Indian J. Technol. 28580

Koraiem A I M, Girgis M M, Khalil Z H and Abu El-Hamd R M 1991 Dyes Pigm. 1589

Kozlov N S, Zhikhareva O D and Batische S A 1972 Khim. Geterotsikl. Soedin. 121619

Mahmoud M R, Khalil Z H and Issa R M 1975 Acta. Chim. Acad. Sci. Hung. 87121

Schimann F 1970 Nuclear magnetic resonance of complex molecules (Braunschweig: Vieweg) vol. $1, \mathrm{p} 41$

Vogel 1956 Text book of practical organic chemistry 3rd edn. (London: Longman) pp 4-123

Weast R C and Astle M J 1980 CRC handbook of chemistry and physics 61st edn (Boca Raton, FL: CRC Press) p 56 